\title{
Pedidos para interrupção de gestação de anencéfalos: jurisprudência no estado de São Paulo
}

\section{Legal requests for anencephalic pregnancies termination: jurisprudence of the state of São Paulo}

\author{
Marcia Vieira da Motta ${ }^{1}$; Monica Vieira da Motta Piacsek ${ }^{2}$; \\ Eliane Vieira da Motta Mollica ${ }^{3}$; Ricardo Nusrala Haddad ${ }^{4}$
}

\begin{abstract}
Motta MV; Piacsek MVM; Mollica EVM; Haddad RN. Pedidos para interrupção de gestação de anencéfalos: jurisprudência no estado de São Paulo. Saúde, Ética \& Justiça. 2013;18(2):146-56.

RESUMO: Em 2012, foi aprovada a legalização do término de gestações de fetos anencéfalos no Brasil pelo Supremo Tribunal Federal (STF). Contudo, os tribunais brasileiros já vinham se posicionando neste sentido por vários anos, com destaque a atuação dos tribunais paulistas. O objetivo deste trabalho foi buscar o posicionamento e as justificativas que serviram de apoio às decisões referentes à interrupção das gestações de anencéfalos e observar na literatura dados referentes aos aspectos médico-legais envolvidos nas decisões. Em São Paulo, foram encontrados 30 acórdãos relacionados ao tema interrupção de gestação de anencéfalos, 9 favoráveis, 6 contrários ao aborto e 15 que não tratavam diretamente o tema. Quando autorizado, o aborto foi realizado tendo como fundamentação jurídica: a) analogia com o aborto terapêutico ou com o sentimental; b) o direito à vida, à saúde, à intimidade, à dignidade e autonomia da gestante; c) a inexigibilidade de conduta diversa da gestante; e d) a equiparação do feto anencéfalo ao morto cerebral. Já os negados, consideraram a primazia do direito à vida do nascituro e a ilegalidade da conduta. Do ponto de vista legal, além dos artigos referentes ao aborto encontrados no Código Penal, foram citados os direitos fundamentais encontrados na Constituição Federal (1988), a Lei no 9.434/97, Lei no 8.069/90, a Declaração Universal dos Direitos Humanos (1948), Declaração Universal dos Direitos da Criança (1959), as resoluções do Conselho Federal de Medicina - CFM n ${ }^{\circ}$ 1.480/97 e 1.752/04, o Pacto de São José (Decreto n ${ }^{\circ}$ 678/92), e a Arguição de Descumprimento de Preceito Fundamental - ADPF no 54 (2008).
\end{abstract}

DESCRITORES: Anencefalia; Aborto induzido/legislação\& jurisprudência.

\footnotetext{
1. Faculdade de Medicina da Universidade de São Paulo

2. Curso de Direito das Faculdades Metropolitanas Unidas

3. Procuradora da Fazenda Nacional

4. Curso de Direito das Faculdades Metropolitanas Unidas

Endereço para correspondência: marcia.motta@gmail.com
} 


\section{INTRODUÇ̃̃O}

$\mathbf{E}$ timologicamente, a palavra anencéfalo tem origem grega, "anegképhalos", que define a ausência da parte do sistema nervoso contida na cavidade craniana ${ }^{1}$. A anencefalia é entendida como uma malformação congênita resultante do defeito de fechamento do tubo neural, ocorrendo por volta do $23^{\circ}$ ao $28^{\circ}$ dia de gestação ${ }^{2}$. Sua origem é multifatorial, destacando-se o papel da deficiência do ácido fólico na gênese da malformação ${ }^{3}$. O diagnóstico é feito de modo seguro durante a gestação, por meio de ultrassonografia a partir do terceiro mês ${ }^{4}$. Supreendentemente, de acordo com a Organização Mundial de Saúde, o Brasil é o quarto país do mundo em incidência de gestações de fetos anencefálicos, ficando somente atrás do México, Chile e do Paraguai 5 .

Em abril de 2012, concluiu-se o julgamento da Arguição de Descumprimento de Preceito Fundamental - ADPF $54^{6}$, com o entendimento pela justiça brasileira de que a interrupção da gravidez de anencéfalos seria apenas a antecipação terapêutica do parto e não constituiria aborto enquanto tipo penal. $\mathrm{O}$ encerramento desta ação constitucional intensificou as discussões dos direitos do nascituro, tanto frente a outras situações de inviabilidade de vida extrauterina, como nos casos de gêmeos xifópagos e dos portadores da Síndrome de Edwards (trissomia do cromossomo 18), como nos casos de aborto como controle de natalidade.

Partindo da análise das decisões dos colegiados paulistas sobre a interrupção da gravidez de anencéfalo, bem como das decisões dos votos da ADPF- $54^{6}$, seria possível discutir os direitos do nascituro e das gestantes no contexto brasileiro, considerando ainda os marcos médico-legais sobre vida e morte vigentes no Brasil: (a) ao respirar o nascituro adquire personalidade jurídica ${ }^{7} ;$ (b) os critérios de morte encefálica consideram os anencéfalos que nascem e respiram, $\operatorname{vivos}^{8,9}$; (c) a interrupção legal da gravidez é aceita apenas para fins terapêuticos ou quando o concepto for resultante de estupro ${ }^{10}$.

\section{OBJETIVO}

O objetivo deste trabalho foi buscar, junto aos acórdãos do Tribunal de Justiça de São Paulo, o posicionamento e as justificativas que serviram de apoio às decisões referentes à interrupção das gestações de nascituros anencéfalos e observar na literatura dados referentes aos aspectos médico-legais envolvidos nas decisões, inclusive da ADPF-54.

\section{METODOLOGIA}

Foi realizada busca ativa no site do Tribunal de Justiça do Estado de São Paulo - TJSP (https://esaj.
tjsp.jus.br/cjsg/resultadoCompleta.do), dos acórdãos contendo os termos, anencefalia e anencéfalo. Todos os documentos foram recuperados em 31/7/2012 e seus textos analisados na íntegra para estabelecer: a) se houve concessão da autorização para a realização da interrupção da gravidez ou não, b) se houve delimitação de um período gestacional limite para a concessão da antecipação terapêutica do parto, c) quais os direitos tutelados referidos nos acórdãos e em que contexto foram discutidos, d) qual a doutrina utilizada para embasar as decisões do ponto jurídico e legal e e) âmbito em que os pedidos foram realizados, civil ou penal. Foram excluídos os acórdãos que tratavam de outros assuntos, como aqueles que apenas citavam anencefalia como exemplo, além daqueles em segredo de justiça.

A tabulação foi feita em planilha MS Excel ${ }^{\circledR}$ de acordo com o tipo, a data de julgamento, o nome do relator e o conteúdo. As análises textuais foram realizadas por dois pesquisadores e os agrupamentos conferidos para que não houvesse qualquer discrepância entre os mesmos. A doutrina, a legislação e a jurisprudência citadas nos documentos foram levantadas em banco de dados digitais (das editoras, dos tribunais, do Ministério da Saúde, do planalto, dos conselhos de classe, das Nações Unidas, da Organização Mundial de Saúde, ou da Câmara dos Deputados):

- http://books.google.com/

- http://portal.cfm.org.br/index. php?option $=$ com_pareceres\&Itemid $=37$

- http://portal.cfm.org.br/index. php?option $=$ com_resolucoes\&Itemid $=36$

- http://portal2.saude.gov.br/saudelegis/leg_ norma_pesq_consulta.cfm

- http://scholar.google.com

- http://www.cremesp.org.br/?siteAcao=Pesqui saLegislacao\&dif $=\mathrm{s}$

- http://www.stf.jus.br/portal/jurisprudencia/ pesquisarJurisprudencia.asp

- http://www.un.org

- http://www.who.int

- http://www2.camara.leg.br/atividadelegislativa/legislacao

- http://www4.planalto.gov.br/legislacao

\section{RESULTADOS}

Foram encontrados 56 acórdãos relacionados aos termos anencefalia ou anencéfalo. Destes, 26 foram excluídos por não se relacionarem diretamente ao tema (apenas citavam o termo em outro contexto). Dos acórdãos selecionados dentro dos critérios de inclusão $(n=30), 9$ foram favoráveis à interrupção da gestação ${ }^{11-19}$, 6 foram contrários ${ }^{20-25}$ e 15 tratavam de assuntos diversos como disputa de jurisdição ou, pela proximidade ou já ocorrência do parto, não tiveram julgamento de mérito 
pela perda do objeto ${ }^{26-40}$. Os votos da ADPF $n^{\circ} 54$ foram avaliados na íntegra ${ }^{6,41,42}$.

Nesta amostra, os principais instrumentos legais utilizados para requisitar o aborto foram mandados de segurança - MS (13) e habeas corpus - HC (10). As datas de julgamento dos acórdãos abrangem o período de abril de 1999 a março de 2012, havendo uma concentração maior a partir de 2006 (22 acórdãos contra 8 do período anterior).
Quando autorizado, o aborto foi realizado tendo como fundamento jurídico: a) a analogia com o aborto terapêutico ou com o sentimental (Tabela 1); b) o direito à vida, à saúde, à intimidade, à dignidade e autonomia da gestante; c) a inexigibilidade de conduta diversa da gestante; e d) a equiparação do feto anencéfalo ao morto cerebral. Já os negados, consideraram a primazia do direito à vida do nascituro e a ilegalidade da conduta, principalmente quando a gestação estava próxima do termo.

Tabela 1- Direitos expressamente tutelados nas ações que autorizaram a realização de aborto junto ao TJSP

\begin{tabular}{|c|c|c|c|c|c|c|}
\hline \multirow[b]{2}{*}{$\begin{array}{c}\text { NÚMERO DA AÇÃO } \\
\text { (FAVORÁVEIS AO ABORTO DO ANENCÉFALO) } \\
n=9\end{array}$} & \multicolumn{6}{|c|}{ DIREITOS TUTELADOS } \\
\hline & 息 & 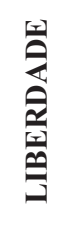 & 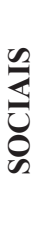 & 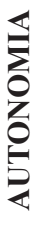 & 劉 & 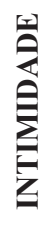 \\
\hline \multicolumn{7}{|l|}{ MS $309.340-3 / 5^{11}$} \\
\hline MS $329.564-3 / 3-00^{12}$ & $\mathrm{X}$ & & & & & \\
\hline MS $498.281-3 / 0-00^{13}$ & $\mathrm{X}$ & $\mathrm{X}$ & $\mathrm{X}$ & $\mathrm{X}$ & & \\
\hline HC 0535559-15.2010.8.26.0000 & $\mathrm{X}$ & & & & & \\
\hline \multicolumn{7}{|l|}{ MS 0011516-37.2010 } \\
\hline MS 0019869-66.2011.8.26.0000 & $\mathrm{X}$ & & & & & \\
\hline MS 0533616-60.2010.8.26.0000 & $\mathrm{X}$ & $\mathrm{X}$ & & $\mathrm{X}$ & & \\
\hline HC 0261073-09.2011.8.26.000 & $\mathrm{X}$ & $X$ & & & $\mathrm{X}$ & $\mathrm{X}$ \\
\hline MS 990.10.381000-7 $7^{19}$ & $\mathrm{X}$ & $\mathrm{X}$ & & $\mathrm{X}$ & & \\
\hline
\end{tabular}

Do ponto de vista legal, além dos artigos referentes ao aborto encontrados no Código Penal ${ }^{10}$, foram citados os direitos fundamentais encontrados na Constituição Federal $^{43}$, a Lei $\mathrm{n}^{\circ} 9.434 / 97^{44}$, Lei $\mathrm{n}^{\circ} 8.069 / 90^{45}$, a Declaração Universal dos Direitos Humanos ${ }^{46}$, Declaração Universal dos Direitos da Criança ${ }^{47}$, as resoluções do CFM n ${ }^{\text {os }} 1.480 / 97^{9}$ e $1.752 / 04^{48}$, o Pacto de São José ${ }^{49}$, e a decisão monocromática da ADPF n ${ }^{\circ} 54^{41}$.

\section{DISCUSSÃO}

Em 30 de abril de 2013, foi publicado o acordão da ADPF $54^{50}$, colocando fim à discussão quanto ao entendimento dos tribunais brasileiros de que a antecipação terapêutica do parto de crianças anencefálicas poderia ser tipificada como um ilícito penal, o aborto. A petição inicial desta ação constitucional havia sido proposta pela Confederação Nacional dos Trabalhadores na Saúde, em 17 de junho de 2004, e levou quase que 10 anos para ser julgada pelo $\mathrm{STF}^{50}$. Ate então, de acordo com o Código
Penal ${ }^{10}$ brasileiro, em apenas duas situações o aborto praticado por médicos seria aceito: quando não houvesse outro meio de salvar a vida da gestante e quando o concepto fosse resultante de estupro ${ }^{10}$.

A primeira sentença conhecida, que autorizou o término seletivo de uma gestação, data de 1989, em Rondônia, foi seguida por outra sentença similar, no Mato Grosso em 1991, está plenamente documentada ${ }^{51}$. Em aproximadamente 15 anos, desde a expedição do primeiro alvará, mais de 5000 alvarás foram concedidos para a interrupção das gestações em casos de anencefalia ${ }^{52}$. De acordo com estes dados, por 23 anos, os pedidos de antecipação terapêutica tramitaram pelos tribunais, tanto cíveis como criminais, e foram julgados refletindo os valores da sociedade brasileira, ora autorizando, ora denegando a demanda.

De acordo com este levantamento feito junto ao TJSP, pode-se avaliar que foram poucos os processos que chegaram à segunda instância em São Paulo, considerando que o e-SAJ (Sistema de Automação da Justiça) permite recuperar as decisões disponibilizadas, 
tanto no Tribunal de Justiça quanto nos extintos Tribunais de alçada, a partir de $1998^{53}$. Pode-se imaginar que isto se deve ao fato de os processos serem relativamente morosos frente à situação clínica que se apresentava aos tribunais, com a descoberta do quadro de anencefalia a partir do $3^{\circ}$ mês gestacional, deixando uma janela temporal pequena para que os tribunais pudessem autorizar a interrupção da gravidez nos casos em que o pedido foi negado em primeira instância. Também é possível cogitar que não tenha havido apelação daqueles casos em que o pedido foi autorizado em primeira instância,

Nos julgamentos avaliados, ficou claro que morte biológica, encefálica e cerebral, eram conceitos por vezes indistintos nos textos recuperados. Os direitos e garantias individuais ora valorizavam a vida do nascituro, ora os direitos relativos à mulher. A idade gestacional como parâmetro para a indicação do aborto ou da antecipação terapêutica da interrupção da gravidez do feto anencéfalo foi citada esporadicamente nos acórdãos, ao contrário do sofrimento psicológico materno ou da generalização dos contextos citados.

Para melhor discutir estes dados, os conceitos foram divididos em subitens que serão explorados na sequência.

Morte encefálica e anencefalia: ausência de vida em ambas as situações?

Tanto a literatura médica quanto a legislação concordam que a morte não é um evento, mas sim um processo e, juridicamente, é considerada como um determinado ponto desse processo biológico ${ }^{3}$. A morte encefálica, neste cenário, apenas atesta inequivocamente a total impossibilidade de vida de um ser humano como indivíduo senciente. Entretanto, como tanto "morte encefálica" quanto "anencefalia" remetem ao termo "encéfalo", imagina-se que a morte e a suposta inexistência do encéfalo tenham o mesmo resultado na prática clínica.

Anatomicamente, o encéfalo corresponde ao telencéfalo (hemisférios cerebrais), diencéfalo (tálamo e hipotálamo), cerebelo, e tronco encefálico (figura 1) ${ }^{54}$. Todavia, o anencéfalo, cujo prefixo grego "an-" sugere ausência de "encéfalo", na realidade pode não apresentar apenas a calota craniana e os hemisférios cerebrais, possivelmente com as demais estruturas do sistema nervoso presentes e funcionais ${ }^{55}$. Como o tronco encefálico mantém-se funcional, podem apresentar reflexos em comum aos de crianças saudáveis ${ }^{56,57}$. Por outro lado, a "morte encefálica" tem a ver com a incapacidade definitiva do seu portador de exercer as funções cerebrais observadas clinicamente por meio de uma série de avaliações que indicam a cessação das atividades do tronco cerebral como um todo . $^{58}$.

Assim, o anencéfalo não pode ser declarado morto só considerando a anatomia do seu sistema nervoso superior.
Seria um ser humano tanto quanto um indivíduo que perdeu parte do seu cérebro num acidente automobilístico ou numa intervenção cirúrgica para extirpação de um tumor maligno ${ }^{59}$. O Ministro Joaquim Barbosa trouxe, ainda, uma outra interpretação à circunstância, quando referiu que o feto anencéfalo "está biologicamente vivo, mas juridicamente morto" 60 .

\section{ENCÉFALO}
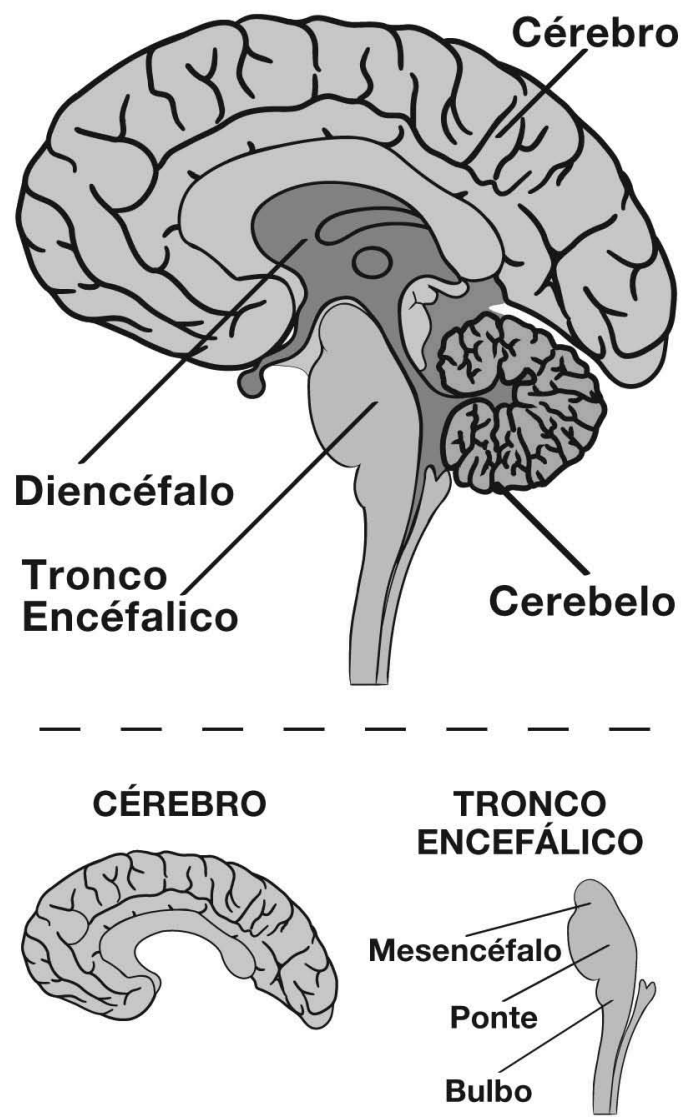

\section{Diagrama das estruturas do encéfalo}

Figura 1 - Desenho esquemático das estruturas do encéfalo Arte da figura: by Criatifik

Esta confusão terminológica refletiu-se nos acórdãos, uma vez que vários consideraram o anencéfalo portador de morte cerebral ou simplesmente como morto em uma caracterização genérica da morte biológica ${ }^{14,16,21}$. Se assim o fosse, não existira vida a ser tutelada e as ações perderiam seu objeto, como citado por Mendez: "um feto anencéfalo é um feto morto" 21 .

As próprias considerações do CFM ao longo dos anos não trouxeram terminologias e conceitos facilmente cognoscíveis quanto às diferenças entre anencéfalo, morto cerebral e morto encefálico, principalmente para aqueles que não são da área da saúde. Em 1991, o CFM 
reconheceu, por meio da Resolução n ${ }^{\circ} 1.346 / 91^{8}$, que a morte encefálica teria equivalência à morte clínica e, em 1997, apresentou critérios para o diagnóstico de morte encefálica a partir de 7 dias de vida (Resolução ${ }^{\circ}$ $1.480 / 97)^{9}$.

De fato, um diagnóstico de morte encefálica equivale ao diagnóstico de morte biológica do ponto de vista médico, religioso e legal. Na infância, os critérios da morte encefálica utilizados no Brasil, assemelhamse aos de outros países e envolvem exames clínicos e complementares realizados em intervalos subsequentes e pré-determinados de acordo com a idade da criança ${ }^{58}$ :

\begin{abstract}
"[...] Art. $4^{\circ}$ Os parâmetros clínicos a serem observados para constatação de morte encefálica são: coma aperceptivo com ausência de atividade motora supraespinal e apneia.

Art. $5^{\circ}$. Os intervalos mínimos entre as duas avaliações clínicas necessárias para a caracterização da morte encefálica serão definidos por faixa etária, conforme abaixo especificado: a) de 7 dias a 2 meses incompletos - 48 horas b) de 2 meses a 1 ano incompleto - 24 horas c) de 1 ano a 2 anos incompletos - 12 horas d) acima de 2 anos - 6 horas.

Art. $6^{\circ}$. Os exames complementares a serem observados para constatação de morte encefálica deverão demonstrar de forma inequívoca: a) ausência de atividade elétrica cerebral ou, b) ausência de atividade metabólica cerebral ou, c) ausência de perfusão sanguínea cerebral.
\end{abstract}

Do ponto de vista médico e legal, os anencéfalos que não respiram ao nascer são considerados natimortos. Neste caso, considera-se nascimento como a expulsão ou extração do feto do útero materno, dentro do período perinatal (a partir da 22 $2^{\mathrm{a}}$ semana gestacional completa, de acordo com a Organização Mundial de Saúde) ${ }^{61}$. Todavia, aqueles que respiram ao nascer, fazem-no de maneira autônoma e, portanto, não apresentam a apneia característica da morte encefálica. Assim, são considerados legalmente vivos e sua morte "biológica" ou clínica por parada cardiorrespiratória ocorre usualmente nos dias seguintes ao nascimento, após repetidos episódios de bradicardia e asfixia ${ }^{57}$. É consequente à disfunção endócrina, à hipotensão arterial, à hipopneia ou à infecção que acometem o recém-nascido, antes que atinja a primeira semana de existência, quando a função do tronco encefálico desaparece ${ }^{58,62}$.

Contudo, em 2004, o CFM considerou que, por serem "natimortos cerebrais" (por não possuírem os hemisférios cerebrais), os critérios de morte encefálica não seriam aplicáveis aos anencéfalos e sua aplicação seria desnecessária (Res. $\left.\mathrm{n}^{\circ} 1.752\right)^{48}$. Esta norma foi posteriormente revogada ${ }^{63}$.

Quando da votação da ADPF 54, dois ministros não foram favoráveis à interrupção terapêutica da gestação do anencéfalo (Ministros Lewandowski e Peluso) e um se absteve (Ministro Dias Toffoli). No voto do ministro relator, a linha de entendimento quanto ao aceite da decisão refletiu claramente as ações prévias favoravelmente julgadas ${ }^{6}$. Tendo como base a inviabilidade extrauterina do feto, o relator reconheceu que este não seria e nem será titular do direito à vida e, deste modo, arguiu que é ninguém.

Neste momento, cabem alguns esclarecimentos biológicos e normativos com relação ao que se entende como vida ou ausência desta. De acordo com Carl Sagan (2010), o famoso exobiologista, não existe uma definição universalmente aceita para o que se entende como vida ${ }^{64}$. Por muitos anos adotou-se o critério de vida de acordo com a capacidade de execução de várias funções, como respiração, por exemplo, e hoje sabe-se que existem exceções como bactérias que não respiram mas vivem pela alteração do estado de oxidação do enxofre. Outro critério de definição seria o da capacidade metabólica em que um ser estaria vivo desde que apresentasse limites definidos e continuamente trocasse parte de seus materiais com o seu meio, sem perder suas propriedades gerais por um período de tempo. Novamente, a regra apresenta exceções como os esporos que podem se manter dormentes por longos períodos e reviver, quando expostos a condições favoráveis.

Sendo assim, de acordo com critérios biológicos, o feto anencéfalo enquanto no útero materno tem sua integridade mantida pela mãe, diferindo de um feto viável por carecer de potencial vital. Não necessariamente teria vida, apenas poder-se-ia garantir que suas células estariam vivas. De qualquer maneira, ao nascer, tornarse-á incapaz de se autorregular e, em termos de todas as definições de vida, morreria. A ideia é complexa e, como o próprio Ministro Marco Aurélio de Mello relatou na ADPF 54, 50\% dos fetos anencefálicos morrem ainda no período intrauterino, ou seja, considera-se, então, que em algum momento $100 \%$ encontravam-se vivos ${ }^{41}$.

\section{Direitos e garantias individuais}

O texto da ADPF-54 destacou que os direitos e garantias individuais são destinados a pessoa e, no caso do anencéfalo, isto nunca ocorrerá, já que não existe potencialidade para tal, uma vez que se trata de "natimorto cerebral". Concluiu que, mesmo admitindo-se que o feto tenha direito à vida, a melhor ponderação seria considerar este valor frente aos diversos outros relativos à mulher como o direito à liberdade, à autodeterminação, à saúde, aos direitos sexuais e reprodutivos bem como à sua dignidade 6 .

Este entendimento quanto à valorização dos direitos da mulher sobre os do feto foi observado em diversos acórdãos, sendo o direito à saúde da gestante o mais comumente observado dentre os acórdãos autorizando a interrupção da gestação (Tabela 1). Em algumas das decisões, os anencéfalos foram considerados 
vivos, porém incapazes para a vida extrauterina, refletindo o entendimento do legislador que as causas de exclusão de ilicitude do aborto seriam aquelas de caráter necessário (único meio de salvaguardar a vida da gestante) e aquelas de caráter sentimental (gravidez resultante de estupro).

É interessante que nos acórdãos não houve ênfase ao disposto no Código Civil (art. $2^{\circ}$ ), de que "a lei põe a salvo, desde a concepção, os direitos do nascituro", independentemente do seu breve potencial de vida, como mencionado pelo Ministro Lewandowski, em seu voto na ADPF-54 ${ }^{42}$. A dignidade humana revestiu-se de uma concepção de liberdade, aquela atribuída à escolha da mulher.

Este conceito também é encontrado na jurisprudência constitucional americana, juntamente com sua interpretação como equidade, status institucional (relativo ao respeito a uma hierarquia social), integridade pessoal e virtude coletiva (respeito à natureza humana) ${ }^{64}$. A Suprema Corte Americana considera, ainda, antiéticas e, portanto, incompatíveis a com dignidade, normas que interfiram com a decisão da mulher em terminar a gravide $z^{64}$. E foi exatamente esta a linha conceitual utilizada nos acórdãos paulistas, muito embora no Brasil esta suposta autonomia não se sustente em situações semelhantes como, por exemplo, nos casos de eutanásia.

\section{Aborto seletivo ou sentimental e idade gestacional}

É importante destacar que, em alguns acórdãos, o aborto seletivo do feto foi equiparado à interrupção eugênica da gravidez ou ao aborto sentimental, sustentado pelo art. $4^{\circ}$ da Lei de Introdução do Código Civil 65: "Quando a lei for omissa, o juiz decidirá o caso de acordo com a analogia, os costumes e os princípios gerais de direito". Na realidade, os procedimentos se distinguem, uma vez que o primeiro é relativo a abortos ocorridos em nome de anomalias fetais incompatíveis com a vida extrauterina (interrupção seletiva), e o aborto eugênico está relacionado às interrupções de gestações por valores étnicos ou de gênero, por exemplo ${ }^{66}$.

O aborto por estupro, ou sentimental, de acordo com a Portaria do Ministério da Saúde - MS n ${ }^{\circ}$ $1.508 / 05^{67}$, envolve a obtenção de diversos termos para sua autorização e não exige decisão judicial para sua autorização ou mesmo Boletim de Ocorrência policial. Deve ser realizado até a $20^{\text {a }}$ semana gestacional, limite considerado por razões médicas operacionais, muito embora, do ponto de vista jurídico, a lei brasileira não estabeleça limites para o aborto com base na idade gestacional $^{68}$. Este parâmetro é o mesmo referido na emblemática decisão da Suprema Corte Americana, no caso Roe v. Wade ${ }^{18}$.

Segundo a literatura, com 24 semanas, já seria possível a sobrevida da criança em uma unidade de tratamento intensivo neonatal e o concepto, deste momento em diante, sentiria dor ${ }^{69}$. O assunto é controverso já que se entende que não há justificativa neurológica para esta afirmação e que, na verdade, a consciência quanto a estímulos dolorosos se dará muito mais tarde na gestação, no terceiro trimestre ${ }^{70}$.

De qualquer modo, o anencéfalo, por não possuir o córtex cerebral, em qualquer das fases da gravidez não conseguiria interpretar os estímulos dolorosos como tais, sendo então de pouco relevância esta consideração no tema. Embora possam responder a estímulos dolorosos ${ }^{71}$ por um reflexo mediado pelo tronco cerebral, não têm consciência do estímulo. A sensação de dor, para ser apreciada e sofrida requer mais do que a presença do tronco cerebral ${ }^{72}$. Nenhum dos acórdãos que autorizou a interrupção da gravidez mencionou a dor fetal, mesmo naqueles com gestações avançadas, tão pouco os que negaram.

A idade gestacional foi mencionada em poucos dos acórdãos deste estudo, sendo a menor igual a 19 semanas $^{18}$. Em um deles, o próprio magistrado referiu que a indicação para a interrupção da gravidez deveria ocorrer, no máximo, até a $25^{\mathrm{a}}$ ou $30^{\mathrm{a}}$ semana de gestação, mas, como no caso em questão a gestante estava por volta da $35^{\mathrm{a}}$ semana, a conduta não seria protegida pelo ordenamento jurídico ${ }^{23}$. Em geral, o limite de 20 semanas do aborto sentimental não foi utilizado como parâmetro em nenhum dos acórdãos.

\section{Sofrimento psicológico materno e familiar: Risco ou perigo de morte?}

Com relação ao sofrimento psicológico de se gestar uma criança com anencefalia, a literatura indica que ele existirá independente da decisão em se manter ou não a gravidez a termo ${ }^{73-75}$. Já quanto aos efeitos da decisão em si, de se interromper uma gestação por anomalias fetais, por qualquer que seja, dependerão de, além das características próprias da gestante e de sua situação familiar, de seus valores culturais e religiosos ${ }^{76-78}$. Seria, deste modo, irresponsável preconizar uma conduta baseada apenas em dados subjetivos.

Com certeza, para alguns, o sofrimento pode diminuir pelo término da gestação. Entretanto, para outros, a culpa advinda desta decisão pode ter efeitos devastadores. De acordo com estudo realizado na Universidade de São Paulo entre 2001 e 2003, o aborto em casos de má-formação fetal só reduziu o sofrimento das gestantes quando esta foi uma escolha feita sem restrições ${ }^{79}$.

Os acórdãos, inclusive da $\operatorname{ADFP~n}^{\circ} 54$, referenciam que o término da gravidez de anencéfalo seria "indicado" pelos transtornos psicológicos que acometem a gestante quando aguarda a evolução natural da gestação. Citam, com frequência, os "prejuizos psicológicos advindos do fato de carregar, por nove meses, em seu ventre, feto sem 
possibilidade de sobrevivência", a preservação do bem estar psicológico e o sofrimento psicológico da mulher 6, 11, 14-16, 19, 22, 40

O trabalho científico utilizado na ADPF $\mathrm{n}^{\circ}$ 54, que indica que as mães sofrem com o diagnóstico da anencefalia, corrobora os achados internacionais, porém sua interpretação com relação à generalização dos efeitos benéficos da conduta de interrupção da gravidez deve ser tomada com cautela, pois o autor deixa claro que a amostra foi composta por pacientes que já haviam decidido abortar, e que, mesmo assim, das 53 gestantes, apenas 35 voltaram para a avaliação psicológica. Destas, 20 expressaram sentimentos negativos com relação à decisão da interrupção e 15 a fizeram por ordem pragmática. 21 destas mulheres $(60 \%)$ recomendariam a alguém na mesma situação a interrupção da gravidez e $32(91,4 \%)$ tomariam a mesma decisão em situação semelhante ${ }^{79}$

\section{A gestante e o feto anencéfalo: a desumanização do concepto}

No direito constitucional americano, a jurisprudência indica, em casos de aborto, uma gestante de certo modo calculista e autônoma. No alemão, a mulher aparece em uma rede de relações humanas em que sua personalidade se expressa acolhida por uma comunidade moral e social maior do que si mesma ${ }^{80}$. Não transparece, nos acórdãos brasileiros, a personalidade da gestante como calculista, autônoma ou, ao contrário, acolhida na sociedade e pela sociedade. A mulher é generalizada, sua dor é generalizada e o caminho para salvaguardá-la é dicotômico. Os acórdãos falam do fardo em se carregar "um feto sem potencial de vida a termo", mas não do fardo que "aquela mulher", em particular, e "aquele feto" estão passando. Do ponto de vista social, tanto ela como o seu concepto não são contextualizados (há poucos acórdãos que mencionam o sofrimento familiar). $\mathrm{O}$ aborto ilegal como um problema de saúde pública não foi mencionado, tampouco os custos sociais relativos aos cuidados com os recém-nascidos anencéfalos, ou mesmo, ao contrário, a possibilidade destes servirem como doadores (pequena, mas existente). A relação médico-paciente que se reflete nos acórdãos é distante, cabendo aos profissionais o diagnóstico anatômico da patologia que acomete o feto, e não o cuidado para com ambos.

É interessante que o direito à saúde sustentou a maioria dos pedidos para a autorização do aborto, como se este fosse restabelecer a saúde psíquica de qualquer mulher naquela situação. Um valor isolado. Nos acórdãos que autorizaram a interrupção da gestação, a terminologia tendeu à neutralidade, mantendo a mulher como gestante e o concepto como feto. Nos que negaram, percebe-se uma situação mais humanizada com a utilização das palavras mãe, nascituro, criança e filho. Neste sentido, é distinto o voto do Desembargador Haddad que contextualiza a situação do caso concreto, mantendo a decisão no âmbito técnico e não moral ${ }^{11,12}$.

\section{CONCLUSÕES}

Os conceitos de morte encefálica e anencefalia se confundem nos acórdãos, grande parte pelo desconhecimento quanto à abrangência anatômica do encéfalo e também quanto aos múltiplos critérios envolvidos na constatação da morte encefálica. O termo natimorto cerebral, estabelecido na resolução de 2004 do CFM, corroborou com a compreensão de que o anencéfalo estaria clinicamente morto. Este fato refletiu em alguns acórdãos que consideraram a conduta de interrupção da gravidez atípica já que o feto anencéfalo não teria vida, de modo que não haveria vida humana a ser tutelada ou crime cometido.

As ações buscaram principalmente afastar a ilicitude da conduta tipificada no Código Penal ${ }^{10}$ valendo-se da analogia com o aborto terapêutico e sentimental (art. 128, I e II) e pouco contribuíram para a discussão do confronto entre os direitos à vida do nascituro e à liberdade da gestante. Quanto aos direitos fundamentais, os direitos à saúde e à liberdade da mulher foram os argumentos mais usados em favor da autorização.

Quanto à idade gestacional e ao aborto, observou-se que juridicamente não houve a adoção de um parâmetro gestacional limite, tanto nas ações que foram prejudicadas pelo estado avançado da gestação ou, ao contrário, naquelas que obtiveram a autorização requerida. Muito embora se tenha adotado o aborto sentimental como paradigma, isto é, a orientação para sua realização até a $20^{a}$ semana de vida intrauterina, não há menção deste fator nos acórdãos.

O fardo psicológico de uma gravidez de risco e sem potencial de êxito vital da criança após o parto foi apresentado de forma generalizada, sem contextualização psicossocial. Muito embora possa ser verdade para muitas grávidas, existem evidências na literatura de que o próprio aborto pode ter efeito avassalador à saúde da mulher. Apesar de ter sido posição minoritária, um dos acórdãos menciona que, frente a esta situação dramática, não se poderia esperar conduta diversa da gestante.

Diante de tantas posições divergentes, inclusive conceituais sobre morte, é importante que se mantenham vivas as discussões sobre o tema. Se norma, fato e valor constroem o ordenamento jurídico, os fatos envolvidos na interrupção de uma gravidez precisam ser mais bem conceituados para que se possa interpretá-los à luz dos valores brasileiros. 
Motta MV; Piacsek MVM; Mollica EVM; Haddad RN. Legal requests for anencephalic pregnancies termination: jurisprudence of the state of São Paulo. Saúde, Ética \& Justiça. 2013;18(2):146-56.

\begin{abstract}
In 2012, the Brazilian Supreme Court (STF) approved the legalization of anencephalic pregnancy termination in Brazil. However, trial courts had already been leaning toward favorable decisions were already positioning themselves in this direction for several years, especially the courts of São Paulo State. The aim of this study was to evaluate the reasoning that Sao Paulo magistrates used to support their decisions regarding their authorizations to terminate anencephalic pregnancies and review the literature regarding the medical-legal aspects involved in their decisions. In São Paulo, there were 30 court rulings regarding anencephalic pregnancy interruption, 9 in favor, 6 against abortion and 15 that did not address the issue directly. When authorized, the abortion was performed, based on the following: a) analogy to therapeutic or sentimental abortion (both authorized by the penal code); b) the right to life, health, privacy, dignity and autonomy of the pregnant woman; c)'unenforceability due to special mental circumstances of ineligibility of a different conduct from the pregnant woman, and d) consideration that considering the anencephalic fetus is as being brain dead. The rulings that denied the abortion, were based on the primacy of the unborn child's right to life and also, by considering the conduct unlawful. From a legal standpoint, in addition to the Penal Code articles pertaining abortion, the following was cited: the rulings cited the constitutional fundamental rights (Brazil, 1988), Laws 9.434/97 and 8.069/90, the Universal Declaration of Human Rights (1948), Declaration of the Rights of the Child (1959), the resolutions of the Federal Council of Medicine (CFM) - 1.480/97 and 1.752/04, the Pact of San José (Decree $n^{\circ}$ 678/92), and the Allegation of Disobedience of Fundamental Rights Precepts - ADPF 54 (2008).
\end{abstract}

KEYWORDS: Anencephaly; Abortion, induced/legislation \& jurisprudence.

\section{REFERÊNCIAS}

1. Cunha AG. Dicionário Etimológico da Língua Portuguesa. Rio de Janeiro: Lexikon Editorial; 2010.

2. Moore KL, Persaud TVN. Embriologia Clinica. $7^{\mathrm{a}}$ ed. São Paulo: Elsevier; 2004.

3. Becker MA. Anencefalia e a oportunidade de interrupção na gravidez. Rev Assoc Med RS. 2007; 51(3): 220-1.

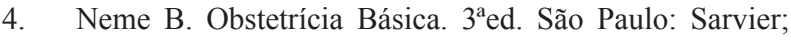
2005. 988p.

5. Organização Mundial de Saúde. Tabela 1A. Anencephaly, live and still births (L+S). 2003 [acesso em 5 jul 2013]. Disponível em: http://www.who.int/genomics/about/en/ anencephaly.pdf

6. Brasil. Supremo Tribunal Federal. Arguição de descumprimento de preceito fundamental 54-8. Voto do Relator: Ministro Marco Aurélio de Melo. Brasília, DF: STF; 12 abr 2012a. Diário da Justiça eletrônico. 30 abr 2013; 80.

7. Brasil. Lei $\mathrm{n}^{\circ} 10.406$, de 10 de janeiro de 2002. Institui o Código Civil. Diário Oficial da União. 11 jan 2002; Seção 1: 1 .

8. Brasil. Conselho Federal de Medicina. Resolução $\mathrm{n}^{\circ}$ 1.346, de 8 de agosto de 1991. Diário Oficial da União. 17 out. 1991; Seção 1, p. 22731.

9. Brasil. Conselho Federal de Medicina. Resolução $\mathrm{n}^{\circ}$ 1.480 , de 8 de agosto de 1997 . A morte encefálica será caracterizada através da realização de exames clínicos e complementares durante intervalos de tempo variáveis, próprios para determinadas faixas etárias. Revoga-se a Resolução CFM n ${ }^{\circ}$ 1.346/91. Diário Oficial da União. 21 ago. 1997; Seção 1, p. 18.227-8.

10. Brasil. Decreto-lei $\mathrm{n}^{\circ} 2.848$, de 7 de dezembro de 1940. Código Penal. Diário Oficial da União. $31 \mathrm{dez}$ 1940; Seção 1: 23911.

11. Tribunal de Justiça do Estado de São Paulo (TJSP). Mandado de Segurança $n^{\circ}$ 309.340-3/5. Relator David
Haddad. 22 mai. 2000a.

12. Tribunal de Justiça do Estado de São Paulo (TJSP). Mandado de Segurança $n^{\circ}$ 329.564-3/3-00. Relator David Haddad. 20 nov. 2000d.

13. Tribunal de Justiça do Estado de São Paulo (TJSP). Mandado de Segurança no 498.281-3/0-00. Se o Código Penai Brasileiro permite a interrupção da gravidez para expulsão antecipai Ia do feto mesmo naqueles casos em que esse feto tenha conformação viável e apresente perspectiva de vida extrauterina saudável (art. 128, incisos I e II, CP), não se iria sustentar que, numa situação aflitiva e dolorosa, em presença de feto anencefálico, o rigor empedernido da lei penal devesse impedir que a mulher pudesse, por sua espontânea vontade (tanto quanto no caso de gestação decorrente de estupro), obter a interrupção de uma gravidez c . L, embora desejada um dia depois (graças ao avanço da Medicina) se comprovou ser totalmente inviável Relator Pires Neto. 8 ago. 2005.

14. Tribunal de Justiça do Estado de São Paulo (TJSP). Habeas Corpus $\mathrm{n}^{\circ}$ 0535559-15.2010.8.26.0000. Relator Aben-Athar. 9 fev. 2011b.

15. Tribunal de Justiça do Estado de São Paulo (TJSP). Mandado de Segurança $n^{\circ}$ 0011516-37.2010. Mandado de segurança. Aborto de indicação "eugênica". Feto anencefálico. Interrupção da gravidez requerida pelos pais. Aplicação analógica, nos termos do art. $4 .^{\circ}$ da Lei de Introdução ao Código Civil, do art. 128, II, do Código Penal (que, dizendo respeito a feto saudável, claramente se aplica, com ainda maior razão, ao caso). Ordem concedida. Relator Francisco Bruno. 24 mar. 2011c.

16. Tribunal de Justiça do Estado de São Paulo (TJSP). Mandado de Segurança $\mathrm{n}^{0}$ 0019869-66.2011.8.26.0000. Mandado de segurança, (pedido para a interrupção de gravidez. Teto anencefálico. Mal formação cerebral do embrião incompatível com a vida extrauterina. anomalia irreversível Manutenção da gravidez trazendo inevitáveis danos psíquicos 
Motta MV et al. Pedidos para interrupção de gestação de anencéfalos: jurisprudência no estado de São Paulo.

à impetrante. Legitimidade do aborto em exame. Ordem concedida, com a expedição de alvará para a interrupção da gestação Relator Penteado Navarro. 14 abr. 2011d.

17. Tribunal de Justiça do Estado de São Paulo (TJSP). Mandado de Segurança $\mathrm{n}^{\circ}$ 053616-60.2010.8.26.0000. Relator Cardoso Perpétuo. 27 jan. 2011e.

18. Tribunal de Justiça do Estado de São Paulo (TJSP). Habeas Corpus $\mathrm{n}^{\circ}$ 0261073-09.2011.8.26.000. Relator Antônio Manssur. 18 jan. 2012a.

19. Tribunal de Justiça do Estado de São Paulo (TJSP). Mandado de Segurança $\mathrm{n}^{\circ}$ 990.10.381000-7. Mandado de Segurança - Ordem concedida. Embora não se desconheça que a questão da interrupção da gravidez é contraditória e muito tormentosa, não se pode deixar de observar que os impetrantes vivem a angústia de suportar no âmbito familiar, a dor trazida pela gestação de um feto acometido de anencefalia, motivo pelo qual, concedesse a segurança Relator Wilson Barreira. 4 nov. 2010c.

20. Tribunal de Justiça do Estado de São Paulo (TJSP). Mandado de Segurança $n^{\circ}$ 376.036-3/3-00. Relator Silva Pinto. 22 abr. 2002.

21. Tribunal de Justiça do Estado de São Paulo (TJSP). Mandado de Segurança n ${ }^{\circ}$ 905.037-3/8. AÇÃO CAUTELAR - Pleito de interrupção de gravidez. Feto anencéfalo. Controvérsia jurídica incidente sobre o tema. Confronto de direitos fundamentais que cede ante a inviabilidade de vida pós-parto. Iminência, entretanto, do parto, face à avançada idade gestacional. Perda do objeto da ação. Recurso provido. Relator Roberto Martins de Souza. 30 jan. 2006c.

22. Tribunal de Justiça do Estado de São Paulo (TJSP). Habeas Corpus $\mathrm{n}^{\circ}$ 01.138.252-3/6. Relator Alfredo Fanucchi. 25 out. $2007 \mathrm{c}$.

23. Tribunal de Justiça do Estado de São Paulo (TJSP). Mandado de Segurança no 516.299-3/5-00. Relator Sebastiao Carlos Garcia. 13 set. 2007d.

24. Tribunal de Justiça do Estado de São Paulo (TJSP). Habeas Corpus n $\mathrm{n}^{\circ}$ 1.165.919-3/1. Relator Luis Pantaleão. 14 jan. 2008a.

25. Tribunal de Justiça do Estado de São Paulo (TJSP). Apelação Criminal $\mathrm{n}^{\circ}$ 990.10.326609-9. Relator Ivan Marques. 18 out. 2010a.

26. Tribunal de Justiça do Estado de São Paulo (TJSP). Mandado de Segurança $n^{\circ}$ 0001037-39.1998.8.26.0000. Impetração por Promotor de Justiça buscando a concessão de efeito suspensivo a apelação interposta contra sentença que deferiu, mediante alvará, a realização de aborto eugênico (feto com formação anencefálica). Informação dando conta da realização do parto e subsequente morte do recém nascido. Pedido prejudicado. Relator Desembargador Passos de Freitas. 6 abr. 1999.

27. Tribunal de Justiça do Estado de São Paulo (TJSP). Mandado de Segurança no 237.941-3/9-00. Relator Prado de Toledo. 9 fev. $2000 \mathrm{~b}$.

28. Tribunal de Justiça do Estado de São Paulo (TJSP). Mandado de Segurança $n^{\circ}$ 311.212-3/1-00. Relator Lustrosa Goulart. 18 mai. 2000c.

29. Tribunal de Justiça do Estado de São Paulo (TJSP). Apelação Civil no 188.859-407. Relator Guimarães e Souza. 24 abr. 2001a.

30. Tribunal de Justiça do Estado de São Paulo (TJSP). Mandado de Segurança $n^{\circ}$ 189.558-4/0-00. Relator Alfredo
Migliore. 24 abr. 2001b.

31. Tribunal de Justiça do Estado de São Paulo (TJSP). Habeas Corpus n ${ }^{\circ}$ 01.020.053-3/6. Relator Alfredo Fanucchi. 30 nov. 2006a.

32. Tribunal de Justiça do Estado de São Paulo (TJSP). Habeas Corpus no 00.909.309-3/9-0000-000. Relator Mario Devienne Ferraz. 3 out. 2006b.

33. Tribunal de Justiça do Estado de São Paulo (TJSP). Habeas Corpus n ${ }^{\circ}$ 01.026.249-3/9-0000-000. Relator Marcos Zanuzzi. 11 jan. 2007a.

34. Tribunal de Justiça do Estado de São Paulo (TJSP). Habeas Corpus n ${ }^{\circ}$ 01.030.821.3/4. Relator Fernando Miranda. 15 mar. $2007 \mathrm{~b}$.

35. Tribunal de Justiça do Estado de São Paulo (TJSP). Mandado de Segurança $n^{\circ}$ 01.061.840-3/2-0000-000. Relator Rene Ricupero. 24 mai. 2007e.

36. Tribunal de Justiça do Estado de São Paulo (TJSP). Habeas Corpus $\mathrm{n}^{\circ}$ 1.172.164.3/1. Relator Guilherme Strenger. 2 jan. 2008b.

37. Tribunal de Justiça do Estado de São Paulo (TJSP). Conflito de jurisdição no $170.724-0 / 0-00$. Relator Maria Olívia Alves. 30 mar. 2009a.

38. Tribunal de Justiça do Estado de São Paulo (TJSP). Habeas Corpus no 990.08.147918-4. Relator Marco Antônio. 5 fev. 2009b.

39. Tribunal de Justiça do Estado de São Paulo (TJSP). Apelação Criminal no 0002767-49.2011.8.26.0576. Relator Francisco Bruno. 28 jun. 2011a.

40. Tribunal de Justiça do Estado de São Paulo (TJSP). Mandado de Segurança $\mathrm{n}^{\circ}$ 001893-12.2012.8.26.0000. Mandado de Segurança Pedido de Interrupção de Gravidez Possibilidade diagnóstico de anencefalia e de risco à saúde da Impetrante Liminar concedida no Plantão Judiciário de $2^{\mathrm{a}}$ Instância durante a suspensão do expediente forense Medida satisfativa Extinção do mandamus com julgamento do mérito. Relator Pedro Menin. 31 jan. 2012b.

41. Brasil. Supremo Tribunal Federal. Arguição de descumprimento de preceito fundamental 54-8. Distrito Federal. Ministro Marco Aurélio de Melo. Brasília, DF: STF; 31 jun 2008. Diário da Justiça eletrônico. 14 ago 2008; 151.

42. Brasil. Supremo Tribunal Federal. Arguição de descumprimento de preceito fundamental 54-8. Voto vencido. Ministro Ricardo Lewandoski. Brasília, DF: STF; 11 abr 2012b [acesso em 5 jun 2013]. Disponível em: http://www.stf.jus.br/arquivo/cms/noticiaNoticiaStf/ anexo/ADPF54RL.pdf

43. Brasil. Constituição (1988). Constituição da República Federativa do Brasil. Brasília, DF: Senado Federal; 1988.

44. Brasil. Lei no 9.434, de 4 de fevereiro de 1997b. Dispõe sobre a remoção de órgãos, tecidos e partes do corpo humano para fins de transplante e tratamento e dá outras providências. Diário Oficial da União. 5 fev 1997; Seção 1: 2191

45. Brasil. Lei ${ }^{\circ} 8.069$, de 13 de julho de 1990. Dispõe sobre o Estatuto da Criança e do Adolescente e dá outras providências. Diário Oficial da União. 16 jul 1990; Seção 1: 13563.

46. Nações Unidas. Declaração Universal dos Direitos Humanos. 1948 [acesso em 5 julho 2013]. Disponível em: http://www.un.org/spanish/Depts/dpi/portugues/ 
Motta MV et al. Pedidos para interrupção de gestação de anencéfalos: jurisprudência no estado de São Paulo.

Universal.html

47. Nações Unidas. Declaração dos Direitos das Crianças. 1959 [acesso em 5 julho 2013]. Disponível em: http:// daccess-dds-ny.un.org/doc/RESOLUTION/GEN/ NR0/142/09/IMG/NR014209.pdf?OpenElement

48. Brasil. Conselho Federal de Medicina. Resolução $\mathrm{n}^{\circ}$ 1.752 , de 8 de setembro de 2004. Autorização ética do uso de órgãos e/ou tecidos de anencéfalos para transplante, mediante autorização prévia dos pais. Diário Oficial da União. 13 nov 2004; Seção 1, p. 140.

49. Brasil. Decreto $\mathrm{n}^{\circ}$ 678, de 6 de novembro de 1992. Promulga a Convenção Americana sobre Direitos Humanos (Pacto de São José da Costa Rica), de 22 de novembro de 1969. Diário Oficial [da] República Federativa do Brasil, Poder Executivo, Brasília, DF, 9 nov 1992; Seção 1: 15562.

50. Brasil. Supremo Tribunal Federal-STF.Acompanhamento Processual. Arguição de Descumprimento de Preceito Fundamental (Med. Liminar) - 54. 2013 [acesso em 5 julho 2013]. Disponível em: http://www.stf.jus.br/portal/ processo/verProcessoAndamento.asp?numero $=54 \&$ class $\mathrm{e}=\mathrm{ADPF} \&$ codigoClasse $=0$ \&origem $=\mathrm{JUR} \&$ recurso $=0 \& \mathrm{ti}$ poJulgamento $=\mathrm{M}$

51. Frigerio MV, Salzo I, Pimentel S, Gollop TR. Aspectos bioéticos e jurídicos do abortamento seletivo no Brasil. Rev Soc Bras Med Fetal. 2001; 7: 15-9.

52. Nobre N. Aborto de feto anencéfalo é motivo de divergências em audiência [Internet]. Câmara Notícias. 10 dez 2009 [acesso em 5 julho 2013]. Disponível em: http://www2.camara.gov.br/agencia/noticias/143951. html

53. Tribunal de Justiça do Estado de São Paulo (TJSP). Cartilha Perguntas Frequentes, versão de 19 de junho de 1992 [acesso em 5 jun 2013]. Disponível em: http://www.tjsp.jus.br/ Download/SIC/CartilhaPerguntasFrequentes.pdf

54. Schmidek WR, Cantos GA. Evolução do sistema nervoso, especialização hemisférica e plasticidade cerebral: um caminho ainda a ser percorrido. Rev Pensamento Biocentrico 2008; 10: 181-204.

55. The Medical task force on anencephaly. The infant with anencephaly. New Engl J Med. 1990; 322(10): 669-74. DOI: http://dx.doi.org/10.1056/NEJM199003083221006

56. Ahmad F. Anencephalic infants as organ donors: beware the slippery slope. Can Med Assoc J. 1992; 146(2): 23644.

57. Cefalo RC, Engelhardt HT Jr. The use of fetal and anencephalic tissue for transplantation. J Med Philos. 1989; 14(1): 25-43.

58. Casella EB. Morte encefálica e neonatos como doadores de órgãos. Pediatria (São Paulo). 2003; 25(4): 184-90.

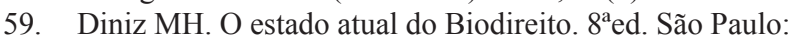
Editora Saraiva; 2011.

60. Brasil. Supremo Tribunal Federal. Habeas Corpus $n^{\circ}$ 84.025. Habeas corpus preventivo. Realização de aborto eugênico. Superveniência do parto. Impetração prejudicada. 1. Em se tratando de habeas corpus preventivo, que vise a autorizar a paciente a realizar aborto, a ocorrência do parto durante o julgamento do writ implica a perda do objeto. 2 . Impetração prejudicada. Relator: Ministro Joaquim Barbosa. Brasília, DF: STF; 4 mar 2004. Diário da Justiça. 25 jun 2004; 121.
61. Organização Mundial de Saúde. Neonatal and perinatal mortality: country, regional and global estimates. France: WHO Press; 2006.

62. Peabody JL, Emery JR, Ashwal S. Experience with anencephalic infants as prospective organ donors. N Engl J Med. 1989; 321: 344-50. DOI: http://dx.doi. org/10.1056/NEJM198908103210602

63. Brasil. Conselho Federal de Medicina. Resolução ${ }^{\circ}$ 1.949, de 10 de junho de 2010. Revoga a Resolução $\mathrm{CFM} \mathrm{n}^{\circ} 1.752 / 04$, que trata da autorização ética do uso de órgãos e/ou tecidos de anencéfalos para transplante, mediante autorização prévia dos pais.. Diário Oficial da União. 6 jul 2010; Seção 1, p. 85.

64. Henry LM. The jurisprudence of dignity. Univ PA Law Rev. 2011-2012; 16:169-233.

65. Sagan C. Definitions of life. In: Bedeau MA, Cleland CF. The Nature of life. New York: Cambridge University Press; 2010. p. 303-6.

66. Brasil. Decreto-lei no 4.657, de 4 de setembro de 1942. Lei de Introdução às normas do Direito Brasileiro. Diário Oficial da União. 9 set 1942; Seção 1: 1.

67. Diniz D, Ribeiro DC. Aborto por anomalia fetal. Brasília: Letras Jurídicas; 2004. 81p.

68. Brasil. Ministério da Saúde. Portaria $\mathrm{n}^{\circ} 1.508$, de $1^{\circ}$ de setembro de 2005. Dispõe sobre o Procedimento de Justificação e Autorização da Interrupção da Gravidez nos casos previstos em lei, no âmbito do Sistema Único de Saúde-SUS. Diário Oficial da União. 2 set 1990; Seção 1: 124.

69. Conselho Regional de Medicina de São Paulo. Parecer $\mathrm{n}^{\circ}$ 21.326, de 1997. Interrupção da gravidez nos casos previstos por lei ou aborto legal. Cons. Cristião Fernando Rosas. 16 mar 1999 [acesso em 5 jun 2013]. Disponível em: http://www.portalmedico.org.br/pareceres/CRMSP/ pareceres/1997/21326 1997.htm

70. Lewis T. Late term abortion: Where is the line between selfishness and life. Una Voce. 2011; 7-11.

71. Lee SJ, Ralston HJ, Drey EA, Partridge JC, Rosen MA. Fetal pain: A systematic multidisciplinary review of the evidence. JAMA. 2005; 294(8): 947-54. DOI: http:// dx.doi.org/10.1001/jama.294.8.947

72. Ohara PT, Vit JP, Jasmin L. Cortical modulation of pain. Cell Mol Life Sci. 2005; 62(1): 44-52. DOI: http://dx.doi. org/10.1007/s00018-004-4283-9

73. White-Van Mourik MC, Connor JM, Fergunson-Smith MA. The psychosocial sequelae of a second trimester termination of pregnancy for fetal abnormality over a two-year period. Birth Defects Orig Artic Ser. 1992; 28(1): 61-74. DOI: http://dx.doi.org/10.1002/pd.1970120308

74. White-Van Mourik MC, Connor JM, Ferguson-Smith MA Patient care before and after termination of pregnancy for neural tube defects. Prenat Diagn. 1990; 10(8): 497-505. DOI: http://dx.doi.org/10.1002/pd.1970100804

75. Bijma HM, van der Heide, Wildschut HJ. Decision making after ultrasound diagnosis of fetal abnormality. Reprod Health Matters. 2008; 16 (31 Supplement): 2-89. DOI: http://dx.doi.org/10.1016/S0968-8080(08)31372-X

76. Korenromp MJ, Page-Christiaens GCML, Van Den Bout J, Mulder EJH, Hunfeld JAM, Potters CMAA, et al. A prospective study on parental coping 4 months after termination of pregnancy for fetal anomalies. Pren Diagn. 
Motta MV et al. Pedidos para interrupção de gestação de anencéfalos: jurisprudência no estado de São Paulo.

2007; 27(8): 709-16. DOI: http://dx.doi.org/10.1002/ pd. 1763

77. Benute GRG, Nomura RMY, Liao AW, Brizot ML, de Lucia MCS, Zugaib M. Feelings of women regarding end-of-life decision making after ultrasound diagnosis of a lethal fetal malformation. Midwifery. 2012; 28(4): 4725. DOI: http://dx.doi.org/10.1016/j.midw.2011.06.011

78. Theofanidis D, Fountouki A, Pediaditaki O. To abort or not? A Greek dilemma - case study. Nurse Educ Today.
2013; 33(6): 644-7. DOI: http://dx.doi.org/10.1016/j. nedt.2012.01.003

79. Benute GRG, Nomura RMY, de Lucia MCS, Zugaib M. Interrupção da gestação apos o diagnóstico de malformação fetal letal: aspectos emocionais. Rev Bras Ginecol Obstet. 2006; 28(1): 10-7. DOI: http://dx.doi. org/10.1590/S0100-72032006000100003

80. Kommers DP. German Constitutionalism: a prolegomenon. Emory Law J. 1991; 40: 837-73.

Recebido em: 08/02/2013

Aprovado em: 28/08/2013 